\title{
Fatores Determinantes do Acesso às Cooperativas de Crédito do Município de Teófilo Otoni - MG: uma Abordagem a Partir do Modelo Logit
}

\section{Determinants of access to Credit Unions in the city of Teófilo Otoni - MG: A Logit Model Approach}

\section{Resumo}

As cooperativas de crédito atuam similarmente a outras instituições financeiras, captando depósitos, oferecendo crédito e prestando serviços diversos de pagamentos e compensação de documentos, entretanto, possuem características próprias, se distinguindo assim, dos bancos convencionais. Por meio da aplicação de questionário a 347 usuários das três cooperativas do município, obteve-se um perfil e identificou-se os fatores socioeconômicos e comportamentais de acesso ao sistema cooperativista. A partir da análise de regressão logística, pôde-se conhecer os fatores que mais determinam o acesso às cooperativas de crédito do município de Teófilo Otoni, que são: rendimento compreendido entre um e cinco salários mínimos; baixa quantidade de serviços utilizados; as cooperativas são a primeira opção em utilizar os serviços bancários; as cooperativas são consideradas melhores que os bancos; indicação da cooperativa; localização da cooperativa.

Palavras-chave: Cooperativismo de Crédito, Determinantes de acesso, Serviços Financeiros.

\begin{abstract}
Credit unions act similarly to other financial institutions, capturing deposits, offering various services and credit payments and compensation documents, however, have their own characteristics, distinguishing themself from conventional banks. Through the application of a questionnaire to 347 users of three unions of the Teofilo Otoni, was obtained, the users profile and could discover the socioeconomic and behavioral factors of access to the cooperative system. From the logistic regression analysis, it was possible to know the factors that determine access to credit unions in the city of Teofilo Otoni, which are: income between one and five minimum wages; low amount of used services; unions are the first option to use banking services; unions are considered better than the banks; indication of the union; union location.
\end{abstract}

Keywords: Credit Unions, Determinants of access, Financial Services.

Recebido: 09/03/2017 Aceito: 06/07/2017

Paulo Deiser Pereira Faria ${ }^{1}$, João Paulo Calembo Batista Menezes ${ }^{2}$, Anelisa de Carvalho Ferreira ${ }^{3}$, Naiara Leite dos Santos Sant'ana ${ }^{4}$, Sabrina Amélia de Lima e Silva ${ }^{5}$

${ }^{1}$ Bacharel em Ciências Contábeis e Pós-graduando em Gestão Municipal, ambos pela Universidade Federal dos Vales do Jequitinhonha e Mucuri, Campus do Mucuri na Cidade de Teófilo Otoni/MG. Pós-graduando em Contabilidade Pública pelo Instituto Superior de Educação Ibituruna - paulodeiser@ hotmail.com - Rua Pedro Rosa Vieira, nº 400, bairro São Bento em Novo Cruzeiro/MG, CEP: 39.820-000

${ }^{2}$ Doutorando em Administração CEPEAD- UFMG - Mestre em Contabilidade pelo ISEG-UTL - Professor Auxiliar da UFVJM

${ }^{3}$ Doutoranda em Administração CEPEAD- UFMG - Mestre em Contabilidade pelo ISCTE-IUL - Professora Assistente da UFVJM

${ }^{4}$ Doutoranda em Administração CEPEAD- UFMG- Mestre em Administração pela UFLA - Professora Assistente da UFJF

${ }^{5}$ Doutoranda e Mestre em Administração CEPEAD- UFMG - Professora Substituta da UFMG 


\section{Introdução}

O cooperativismo é um movimento internacional, com origem nas civilizações antigas e ganho de expressividade ao longo da Revolução Industrial no século XIX, como tentativa de redução das desigualdades econômicas e sociais. O movimento procura construir uma sociedade mais justa, igualitária e solidária por meio de boas práticas de ajuda mútua (SANTOS, GOUVEIA e VIEIRA, 2008; VENTURA, FILHO e SOARES, 2009). Para Pinheiro (2008, p.07) “Cooperativas de Crédito são instituições financeiras constituídas sob forma de sociedade cooperativa, tendo por objetivo a prestação de serviços financeiros aos associados, como concessão de crédito, captação de depósito à vista e a prazo, entre outras".

As cooperativas de crédito estão inseridas no meio econômico financeiro do Brasil desde 1902 e se apresentam com especial importância para a sociedade brasileira à medida que promovem a aplicação de recursos privados e públicos, assumindo riscos em favor da comunidade onde está inserida (ORGANIZAÇÃO DAS COOPERATIVAS BRASILEIRAS,

2016). O cooperativismo deixou de ser apenas uma simples alternativa de mercado, e atingiu um modelo empresarial relevante em épocas economicamente difíceis. As cooperativas de crédito são instituições financeiras que tornam o acesso a crédito mais fácil e barato, visto que reduzem os juros bancários, especialmente as taxas de cheque especial e de empréstimos (GONÇALVES; BRAGA, 2008).

De acordo com o BACEN (2016) cooperativa de crédito é uma instituição financeira formada pela associação de pessoas para prestar serviços financeiros aos seus associados. Os cooperados são ao mesmo tempo donos e usuários da cooperativa, participando de sua gestão e usufruindo de seus produtos e serviços. Eles encontram os principais serviços disponíveis nos bancos, e têm poder igual de voto independentemente da sua cota de participação no capital social da cooperativa. O cooperativismo não visa lucros, os direitos e deveres de todos são iguais e a adesão é livre e voluntária.

As cooperativas de Crédito estão enquadradas no Sistema Financeiro Nacional (SFN) como Instituições Financeiras não bancárias, integrando o subsistema de intermediação financeira (ASSAF NETO. 2014). Em relação aos demais segmentos do mercado financeiro nacional, o cooperativismo é o que possui a maior quantidade de instituições autorizadas a funcionar segundo o Banco Central do Brasil BACEN (2016a). Essa elevada quantidade de instituições veem contribuindo para o crescimento da participação no consolidado dos ativos financeiros do SFN, sendo estas classificadas em conjunto, em sexto lugar entre as maiores instituições financeiras do país, onde se incluem o Banco Cooperativo do Brasil S.A. (BANCOOB) e o Banco Cooperativo Sicredi S.A. (BanSicredi).

Atentando-se ao contexto financeiro nacional atual, baseado em altas taxas de juros, inflação desregulada, altas taxas de desemprego, crises políticas e de credibilidade do sistema perante o mercado, no qual os bancos se esforçam para obter clientes e se utilizam, em alguns casos, de ações escusas se para mantê-los, as cooperativas veem se destacando tanto em quantidade como em participação no consolidado do Sistema Financeiro Nacional. Tem-se observado uma crescente aderência às cooperativas nos últimos anos em diversos municípios brasileiros, e tal fato poderia ser explicado pelas melhores taxas e tarifas, acesso, facilidade de negociação entre outros.

O objetivo do estudo foi analisar o perfil dos usuários de cooperativas, para tanto observou-se os fatores socioeconômicos e comportamentais de ingresso ao sistema cooperativista e os motivos de acesso dos cooperados às cooperativas de crédito do município de Teófilo Otoni/MG. Os objetivos específicos foram constituídos pela análise da utilização dos serviços; análise da avaliação dos serviços; e análise do acesso às cooperativas por associados e não associados.

Esse tema mostra-se relevante para a região do Vale do Mucuri - MG visto a necessidade de desenvolvimento econômico e regional; grande quantidade de trabalhadores informais, e necessidade de se buscar crédito; e pela ocorrência de trabalhadores e empresários rurais com necessidade de financiamento para as suas atividades. Conhecer o perfil dos usuários pode ser fator preponderante para o desenvolvimento econômico e social da região por meio do fomento do acesso ao capital. Por meio dos resultados da pesquisa as cooperativas podem adequar seus produtos e financiamentos ao público usuário dos serviços e potenciais entrantes. Por último salienta-se a riqueza desse tipo de trabalho para a academia, que acontece por meio da 
aliança entre a ciência e a preocupação social, fatores esses preponderantes ao desenvolvimento do país e sociedade.

\section{Revisão de Literatura}

A cooperativa de crédito é uma forma de organização socioeconômica, a qual é uma fonte de recursos não somente para consumidores de crédito, mas também para aplicadores. Alguns cooperados podem usar estas cooperativas exclusivamente para aplicações de recursos financeiros, enquanto outros as consideram como fonte de consumo de crédito (BRESSAN; BRAGA; BRESSAN, 2012). Taylor (1971) afirma que uma das características das cooperativas não é o lucro individual, mas sim o alcance dos objetivos econômicos e sociais do grupo. O comportamento econômico nas cooperativas pode então ser visto como uma extensão do comportamento econômico dos seus membros, oposto ao comportamento individual independente.

Segundo a Organização das Cooperativas Brasileiras (OCB, 2016), no Brasil existem cooperativas em 13 setores da economia. Assim, estabeleceu-se os ramos do cooperativismo baseados nas diferentes áreas de sua atuação: Agropecuário;
Consumo; Crédito; Educacional; Especial; Habitacional; Infraestrutura; Mineral; Produção; Saúde; Trabalho; Transporte; Turismo e Lazer. Observa-se uma elevação no número de cooperativas de crédito nas décadas de 40,50 e 60 devido à popularização das mesmas em todas as regiões do Brasil. Na década seguinte, percebe-se uma redução significativa no número de cooperativas de crédito. Esse fato é explicado pelo "golpe militar de 1964", no qual todas as centrais de cooperativas de crédito brasileiras foram eliminadas entre os anos de 1964 a 1970 e impediram a criação de novas cooperativas, principalmente do tipo Luzzatti (PINHO; PALHARES, 2010).

Após a promulgação da Constituição Federal de 1988 observou-se grande aumento de cooperativas de crédito devido aos incentivos existentes na época. Nas décadas seguintes, começa uma estagnação desses números, devido a processos de cancelamentos por inatividade operacional e ingressos no regime de liquidação ordinária. Além disso, ocorreram também várias incorporações resultantes do processo em curso de fortalecimento do setor cooperativista de crédito (PINHEIRO, 2008). O Gráfico 01 demonstra a evolução do número de cooperativas de crédito de 1940 a 2015.

\section{Gráfico 01 - Evolução das Cooperativas de Crédito}

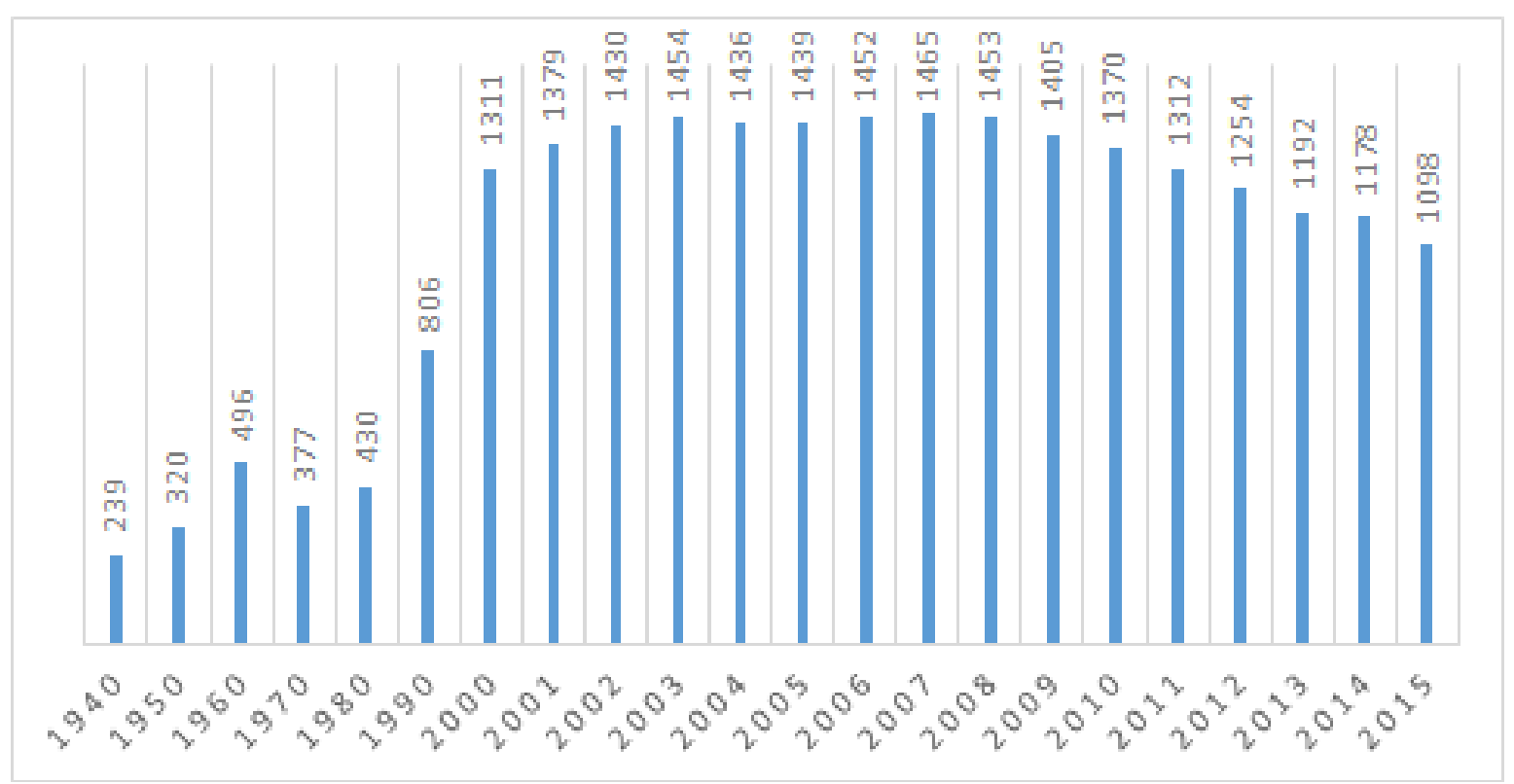

Fonte: Elaborado com base em Pinheiro (2008, p. 13); Banco Central do Brasil (2016)

Segundo Pinheiro (2008) as Cooperativas de Crédito são divididas em três níveis/graus, são eles:
Cooperativas singulares ou de $1^{\circ}$ grau: que prestam serviços financeiros de captação e de crédito apenas 
aos respectivos associados, podendo receber repasses de outras instituições financeiras e realizar aplicações no mercado financeiro; Cooperativas centrais e federações de cooperativas ou de $2^{\circ}$ grau: são aquelas constituídas por cooperativas singulares e que objetivam organizar, em comum e em maior escala, os serviços econômicos e assistenciais de interesse das filiadas, integrando e orientando suas atividades, bem como facilitando a utilização recíproca dos serviços; e Confederações de cooperativas ou de $3^{\circ}$ grau: as constituídas por centrais e federações de cooperativas e que têm por objetivo orientar e coordenar as atividades das filiadas, nos casos em que o vulto dos empreendimentos transcorrer o âmbito de capacidade ou conveniência de atuação das centrais ou federações.

\subsection{Contexto do Cooperativismo de Crédito em 2014}

Na Tabela 1, pode-se observar o Market Share de algumas das maiores Instituições financeiras do Brasil e das Cooperativas de Crédito, segundo a relação divulgada pelo Banco Central do Brasil, contendo os 50 maiores bancos e consolidados do Sistema Financeiro Nacional, tendo como data base o mês de março de 2014, através dos balancetes processados até o dia 02 de junho de 2014.

Tabela 1 - 50 Maiores Bancos e o Consolidado do Sistema Financeiro Nacional

\begin{tabular}{|c|c|c|c|c|c|c|c|}
\hline $\begin{array}{c}\text { Posiçã } \\
\text { o }\end{array}$ & $\begin{array}{l}\text { Instituição } \\
\text { Financeira }\end{array}$ & $\begin{array}{l}\text { Ativos } \\
\text { Totais }\end{array}$ & $\begin{array}{c}\text { \% de } \\
\text { Ativo } \\
\text { S } \\
\text { Totai } \\
\text { S } \\
\end{array}$ & Depósitos & $\begin{array}{c}\% \\
\text { de } \\
\text { Depósi } \\
\text { tos }\end{array}$ & $\begin{array}{c}\text { Patrimôn } \\
\text { io } \\
\text { Líquido }\end{array}$ & $\begin{array}{c}\% \\
\text { Patrimôn } \\
\text { io } \\
\text { Líquido }\end{array}$ \\
\hline $1^{\circ}$ & $\begin{array}{c}\text { Banco do } \\
\text { Brasil }\end{array}$ & $\begin{array}{c}1.280 .779 .07 \\
1\end{array}$ & 18,88 & $\begin{array}{c}482.501 .75 \\
7\end{array}$ & 25,25 & $\begin{array}{c}72.096 .74 \\
0\end{array}$ & 13,45 \\
\hline $2^{\circ}$ & Itaú & $\begin{array}{c}1.033 .933 .85 \\
7\end{array}$ & 15,24 & $\begin{array}{c}293.130 .62 \\
1\end{array}$ & 15,34 & $\begin{array}{c}89.836 .29 \\
0\end{array}$ & 16,76 \\
\hline $3^{\circ}$ & $\begin{array}{c}\text { Caixa } \\
\text { Econômica } \\
\text { Federal }\end{array}$ & 910.190 .024 & 13,41 & $\begin{array}{c}374.857 .36 \\
8\end{array}$ & 19,61 & $\begin{array}{c}26.686 .87 \\
0\end{array}$ & 4,98 \\
\hline $4^{\circ}$ & Bradesco & 790.685 .851 & 11,65 & $\begin{array}{c}219.741 .07 \\
0\end{array}$ & 11,50 & $\begin{array}{c}73.529 .85 \\
4\end{array}$ & 13,71 \\
\hline $5^{\circ}$ & Santander & 503.452 .022 & 7,42 & $\begin{array}{c}133.480 .21 \\
0\end{array}$ & 6,98 & $\begin{array}{c}58.180 .51 \\
6\end{array}$ & 10,85 \\
\hline $\begin{array}{c}6^{\circ} \\
17^{\circ}\end{array}$ & $\begin{array}{l}\text { HSBC } \\
\text { Banco }\end{array}$ & 167.395 .337 & 2,47 & 57.133 .280 & 2,99 & 9.973 .788 & 1,86 \\
\hline & $\begin{array}{l}\text { Cooperativo } \\
\text { Sicredi S.A. }\end{array}$ & 24.067 .866 & 0,35 & 10.396 .285 & 0,54 & 827.040 & 0,15 \\
\hline $20^{\circ}$ & BANCOOB & 20.804 .196 & 0,31 & 15.512 .142 & 0,81 & 607.842 & 0,11 \\
\hline & $\begin{array}{l}\text { Cooperativas } \\
\text { de Crédito }\end{array}$ & 131.567.021 & 1,94 & 60.918 .004 & 3,19 & 23.782.477 & 4,44 \\
\hline & TOTAL & 6.784.887.032 & & 1.911.260.749 & & 536.155.404 & \\
\hline
\end{tabular}

Fonte: Adaptado de BACEN (2014) posição de março. Valores monetários em R \$ mi

Em abril de 2014, o sistema cooperativista de crédito brasileiro possuía 1.178 cooperativas de crédito (centrais e singulares) espalhadas pelos Sistemas Sicoob Brasil, Sicredi Serviços, Unicred,
Confesol, outros sistemas menores e as cooperativas independentes. Juntas, possuíam um ativo total de $\mathrm{R} \$$ 131.567.021, representando $1,94 \%$ do ativo total do Sistema Financeiro Nacional. Somando os ativos das 
cooperativas de crédito com os ativos de seus Bancos Cooperativos, BANCOOB e BANSICRED, seus valores chegavam a $\mathrm{R} \$ 176.439 .083$, representando 2,60\% do ativo total do Sistema Financeiro Nacional.

Pinho e Palhares (2010) afirmam que os motivos do cooperativismo de crédito brasileiro não ter conseguido uma maior participação do movimento bancário nacional, sendo que o cooperativismo de crédito abrange quase todo o território nacional, fazendo-se presente em todos os estados brasileiros e no distrito federal, onde se destaca um grande número de cooperativas e até mesmo de associados. Os autores explicam que existem diversas razões, podendo se destacar principalmente a falta de conhecimento da grande maioria dos associados sobre o real significado do cooperativismo e sua valiosa participação na cooperativa, o medo do associado em colocar todos os seus recursos na "pequena" cooperativa, e o fato da cooperativa nem sempre ter disponibilidade para conceder empréstimos e não possuir todos os serviços que o associado precisa.

Tendo em vista este contexto, verificaremos os fatores determinantes para o acesso aos serviços financeiros das cooperativas de crédito do município de Teófilo Otoni - MG.

\section{Metodologia}

A presente pesquisa classifica-se como descritiva quanto aos objetivos, e relativamente aos procedimentos técnicos foi aplicada a técnica por levantamento. Quanto à abordagem do problema foi realizada uma pesquisa quantitativa.

No segundo trimestre de 2014, existiam no Brasil 1.178 Cooperativas de Crédito BACEN (2014a), 200 localizadas em Minas Gerais segundo o Anuário de Informações Econômicas e Sociais do Cooperativismo Mineiro publicado pela OCEMG. Dentre as 1.178 Cooperativas, 02 estavam inseridas no município de Teófilo Otoni, porém, a Sicoob AC Credi também estava presente como Posto de Atendimento (PA), totalizando assim 03 cooperativas de crédito em Teófilo Otoni.

Desta forma foram abrangidas as 03 Cooperativas no estudo, constituindo o local de realização desta pesquisa, sendo elas: Cooperativa de Crédito de Livre Admissão Vale do Mucuri Ltda - SICOOB CREDIVALE; Cooperativa de Economia e Crédito Mútuo dos Comerciantes de Materiais de
Construção de Governador Valadares Ltda. SICOOB AC CREDI; e Unicred Três Vales.

A informação do número de associados foi cedida pelas próprias cooperativas: Credivale 1.943 associados; a AC Credi 955 associados e a Unicred Três Vales 656 associados, sendo um total de 3.554 associados ao cooperativismo de crédito no município de Teófilo Otoni no mês de maio de 2014, obtendo-se a população finita da pesquisa.

Beuren (2013) define a amostragem aleatória simples como um processo equivalente a um sorteio lotérico, no qual, a unidade da população de pesquisa possui a mesma probabilidade de ser selecionada. Tratando-se, basicamente de um sorteio, os números podem ser escolhidos diversas vezes, de forma que o tamanho da população persista constante durante o processo de seleção.

Para determinar o tamanho da amostra foi utilizada a estatística inferencial que, segundo Triola (2013) se preocupa com o raciocínio necessário para a partir dos dados, se obterem conclusões gerais. $\mathrm{O}$ mesmo ainda cita que, existem duas aplicações da inferência estatística envolvendo o uso de dados amostrais, são elas: estimar o valor de um parâmetro populacional e testar alguma afirmação (ou hipótese) sobre uma população.

Triola (2013) afirma que o nível de confiança de $95 \%$ é o mais usado em cálculos de amostras finitas, assim, o mesmo foi utilizado neste trabalho. $\mathrm{O}$ autor afirma que o valor crítico a se usar para esse tipo de nível de confiança é de 1,96. A margem de erro empregada na pesquisa constituiu-se de $5 \%$. Desta forma, obteve-se uma amostra de 347 associados, sendo de forma estratificada: 190 do Sicoob Credivale, 93 do Sicoob Ac Credi e 64 na Unicred Três Vales.

A pesquisa foi conduzida considerando que mesmo autodeclarados não associados, os entrevistados seriam mantidos na amostra, uma vez que utilizaram o serviço de uma cooperativa, mesmo existindo outras 6 instituições financeiras não cooperativas na cidade, ou até mesmo o fizeram em nome ou solicitação de um cooperado. O instrumento de coleta de dados utilizado na pesquisa foi $\mathrm{o}$ questionário estruturado. $\mathrm{O}$ mesmo foi concebido em três blocos de perguntas, sendo que o primeiro bloco retrata o perfil dos usuários dos serviços das cooperativas de crédito, o segundo bloco é constituído pela utilização dos serviços 
financeiros e o terceiro bloco faz a avaliação dos serviços pelo entrevistado.

$\mathrm{O}$ roteiro de entrevista foi utilizado com o objetivo de levantar as variáveis socioeconômicas e comportamentais das pessoas que possuem acesso ao sistema cooperativista de crédito do município de Teófilo Otoni. Parte do bloco 03 continha possibilidades de resposta em escala do tipo Likert (uma escala psicométrica que pretende registrar $\mathrm{o}$ nível de concordância ou discordância com uma declaração dada), variando das opções "muito insatisfeito" a "muito satisfeito" com numeração crescente e nesta ordem de concordância, havendo perguntas que possibilitaram uma análise de dependência entre as duas ou mais variáveis. A Tabela 02 apresenta as variáveis estudadas neste trabalho.

\section{Tabela 02 - Variáveis da pesquisa}

\begin{tabular}{|c|c|}
\hline Nome da variável & Descrição \\
\hline \multicolumn{2}{|c|}{ Variável Dependente } \\
\hline Incl & Acesso e uso de serviços financeiros $(1=$ cooperado / $0=$ não cooperado $)$ \\
\hline \multicolumn{2}{|c|}{ Variáveis Independentes } \\
\hline Ori & Local onde foi feita a entrevista. \\
\hline Gen & Género (sexo do entrevistado). \\
\hline$I d a$ & Idade do entrevistado (medida pelos números de anos). \\
\hline Esc & Nível de instrução (medido pelos números de anos de escolaridade). \\
\hline Estciv & Estado civil do entrevistado (solteiro, casado, divorciado, viúvo, outros). \\
\hline Zon & Localização geográfica (zona rural ou zona urbana). \\
\hline Mca & Quantidade de pessoas que moram na casa e parentesco. \\
\hline Profi & Profissão do entrevistado. \\
\hline Ren & Rendimento compreendido entre um e acima de cinco salários mínimos. \\
\hline Qcont & Quantidade de contas correntes e/ou poupanças no SF. \\
\hline Qserv & Quantidade de serviços utilizados. \\
\hline Freq. & Frequência de visitas na agência (quantidade de vezes que vai na agência). \\
\hline Tcoop & Tempo como cooperado (tempo de conta na cooperativa). \\
\hline Mot & Motivos que levaram a se associar. \\
\hline Popç & Cooperativa como primeira opção em utilizar os serviços bancários. \\
\hline Mban & Cooperativa melhor que bancos. \\
\hline Ind & Indicação da cooperativa. \\
\hline Aten & Satisfação em relação ao atendimento em geral \\
\hline Sserv & Satisfação em relação aos serviços \\
\hline Sprd & Satisfação e relação aos produtos \\
\hline$E d u$ & Educação e cortesia no atendimento \\
\hline Loc & Localização da cooperativa \\
\hline Tar & Satisfação com tarifas cobradas \\
\hline $\operatorname{Tax}$ & Satisfação com taxas cobradas \\
\hline$E s p$ & Tempo de espera para ser atendido \\
\hline Conh & Conhecimento sobre cooperativismo \\
\hline Lit & Informações básicas para gestão do seu dinheiro \\
\hline Bur & Burocracia nos procedimentos para utilização dos produtos/serviços \\
\hline Conf & Confiança na cooperativa \\
\hline Int & Interesse da cooperativa pela comunidade \\
\hline
\end{tabular}

Fonte: Questionário da pesquisa (2014) 
As entrevistas foram realizadas entre os dias 29 de setembro a 10 de outubro de 2014 nas cooperativas mencionadas anteriormente, sendo que os entrevistados foram abordados após a utilização dos serviços. Os dados obtidos foram tabulados no Microsoft Excel 2010 e em seguida tratados no software Statistic Package for the Social Sciences (SPSS), na versão 22.0 para a verificação dos dados.

O tratamento dos dados quantitativos ocorreu por meio das técnicas estatísticas uni e bivariada para descrever a amostra. Foi apurada a distribuição de frequência do questionário em consonância com os três blocos do mesmo, assim como a regressão logística que se caracteriza, segundo Corrar, Paulo e Dias Filho (2014, p.284), como "uma técnica estatística que nos permite estimar a probabilidade de ocorrência de um determinado evento em face um conjunto de variáveis explanatórias, além de auxiliar na classificação de objetos ou casos". Ainda segundo os autores a principal característica deste método é que a variável dependente é dicotômica, exigindo que o resultado da análise permita associações a determinadas categorias, como positivas ou negativas, aceitar ou rejeitar e assim por diante.

De acordo com Gujarati (2006) existem três abordagens para formalizar um modelo de escolha binária, nomeadamente o modelo de probabilidade linear, modelo logit, e modelo probit, sendo a escolha do modelo apropriado entre o Probit e Logit uma escolha arbitrária e de conveniência matemática. No presente trabalho foi utilizado o modelo Logit para avaliar a probabilidade de utilização dos serviços por associados e não associados.

\section{Análise dos Dados}

\subsection{Perfil dos Entrevistados}

O primeiro bloco do roteiro de entrevista, representado por meio do Quadro 01 buscou revelar o perfil do entrevistado, as características dos frequentadores das cooperativas, tendo como variáveis o gênero, a faixa etária, o nível de instrução, o estado civil, a localização geográfica, a organização coletiva (famílias), a profissão e a renda familiar. A amostra deste estudo totalizou 347 entrevistados escolhidos aleatoriamente no efetivo acesso e uso dos serviços.

\section{Quadro 01 - Perfil do Entrevistados}

\begin{tabular}{|c|c|}
\hline Gênero & $56,2 \%$ masculino e $43,8 \%$ feminino \\
\hline Faixa etária & $\begin{array}{l}9,5 \% \text { idade até os } 20 \text { anos; } 23,1 \% \text { de } 21 \text { a } 30 \text { anos; } 30,3 \% 31 \text { a } 40 \text { anos; } 15 \% 41 \text { a } 50 \text { anos; } 15,3 \% \\
51 \text { a } 60 \text { anos; } 4,6 \% \text { acima de } 60 \text { anos; } 2,3 \% \text { não informaram a idade. }\end{array}$ \\
\hline $\begin{array}{l}\text { Nível de } \\
\text { instrucão }\end{array}$ & $\begin{array}{l}31 \% \text { ensino médio/técnico; } 14,5 \% \text { ensino fundamental/médio incompleto; } 20 \% \text { superior completo; } \\
21.5 \% \text { superior incompleto; } 9.5 \% \text { pós-graduacão; } 2 \% \text { mestrado/doutorado; } 1.5 \% \text { não alfabetizados. }\end{array}$ \\
\hline Estado civil & $\begin{array}{c}45,5 \% \text { solteiros; } 40,1 \% \text { casados; } 5,2 \% \text { separados/divorciados; } 5,2 \% \text { viúvos; } 4 \% \text { não informaram ou } \\
\text { possuem outras formas de estado civil }\end{array}$ \\
\hline $\begin{array}{l}\text { Localização } \\
\text { geográfica }\end{array}$ & $83 \%$ residem em meio urbano; $17 \%$ zona rural. \\
\hline $\begin{array}{l}\text { Família como } \\
\text { eixo da } \\
\text { sociedade }\end{array}$ & $\begin{array}{c}\text { O questionário possibilitou mostrar como está organizada a coletividade dos usuários das } \\
\text { cooperativas de crédito, sendo a família considerada como um dos principais eixos da sociedade. } \\
\text { Essa unidade doméstica pode ser de três tipos: unipessoal (quando é composta por uma pessoa } \\
\text { apenas) } 9,8 \% \text {, de duas pessoas ou mais com parentesco } 70,89 \% \text { ou de duas pessoas ou mais sem } \\
\text { parentesco entre elas, sendo de } 19,31 \% \text {. }\end{array}$ \\
\hline Profissão & $\begin{array}{l}\text { 41\% empregados do setor privado; } 15 \% \text { empregadores ou proprietários de empresas; } 13 \% \\
\text { profissionais liberais; } 7 \% \text { funcionários públicos ou economia mista; } 6 \% \text { aposentados e pensionistas; } \\
18 \% \text { outra profissão (estudante, autônomo etc). }\end{array}$ \\
\hline $\begin{array}{l}\text { Renda familiar } \\
\text { mensal }\end{array}$ & $\begin{array}{l}\text { 22,5\% um salário mínimo; } 23,1 \% \text { renda entre } 01 \text { e } 02 \text { salários mínimos; } 20,5 \% \text { mais de } 02 \text { e menos } \\
\text { de } 03 \text { salários mínimos; } 9,5 \% \text { mais de } 03 \text { e menos de } 04 \text { salários mínimos; } 6,9 \% \text { mais de } 04 \text { e } \\
\text { menos de } 05 \text { salários mínimos; } 17,6 \% \text { renda acima de } 05 \text { salários mínimos. }\end{array}$ \\
\hline
\end{tabular}

Fonte: Dados da pesquisa (2014) 
Para reafirmar os dados obtidos e citados no estudo, optou-se pela verificação por meio da estatística descritiva dos fatores socioeconômicos do bloco 01 do roteiro de entrevista, elencadas na Tabela 03.
Ela retrata o número de entrevistados em cada variável $(\mathrm{N})$, a média aritmética das respostas, o desvio padrão e a variância.

Tabela 03 - Bloco 01 - Perfil do entrevistado

\begin{tabular}{lcccc}
\hline \multicolumn{1}{c}{ Variável } & N & Média & $\begin{array}{c}\text { Desvio } \\
\text { Padrão }\end{array}$ & Variância \\
\hline \hline Local da entrevista [ori] & 347 & 1,64 & 0,776 & 0,602 \\
$\begin{array}{l}\text { Gênero do entrevistado } \\
\text { [gen] }\end{array}$ & 347 & 1,44 & 0,497 & 0,247 \\
Faixa etária [ida] & 347 & 3,27 & 1,446 & 2,091 \\
Nível de instrução [esc] & 347 & 3,81 & 1,329 & 1,765 \\
Estado civil [estciv] & 347 & 2,17 & 1,192 & 1,421 \\
$\begin{array}{l}\text { Localização geográfica } \\
\text { [zon] }\end{array}$ & 347 & 1,17 & 0,376 & 0,142 \\
Quantidade de moradores & 347 & 2,61 & 0,659 & 0,435 \\
[mca] & & & & \\
$\begin{array}{l}\text { Profissão do entrevistado } \\
\text { [profi] }\end{array}$ & 347 & 4,09 & 1,667 & 2,779 \\
$\begin{array}{l}\text { Renda familiar [ren }] \\
\text { TOTAL VÁLIDOS }\end{array}$ & 347 & 3,08 & 1,757 & 3,086 \\
\hline
\end{tabular}

Fonte: Dados da pesquisa (2014)

\subsection{Análise dos Serviços}

No segundo bloco do roteiro de entrevista, representado por meio do Quadro 02, foi analisada a utilização dos serviços pelos entrevistados. Levou-se em conta a quantidade de contas no sistema financeiro do município, os serviços que foram utilizados, a frequência de visitas na agência, o tempo de conta naquela cooperativa (se associado) e os motivos que levaram a se associar (se associado).

\section{Quadro 02 - Utilização dos Serviços}

\begin{tabular}{|l|l|}
\hline $\begin{array}{l}\text { Quantidade de } \\
\text { contas no sistema } \\
\text { financeiro }\end{array}$ & $\begin{array}{l}\text { 41,2\% uma conta; } 41,8 \% \text { duas contas; } 13,5 \% \text { três contas e cerca de 2\% quatro contas. } \\
\text { Apenas 1,2\% não possuem nenhuma conta no sistema e não houve casos com cinco ou } \\
\text { mais contas, seja em bancos e cooperativas de crédito do município. Sobre a contagem } \\
\text { de contas que os entrevistados possuem, verificou-se que a maioria dos entrevistados } \\
\text { possui conta no Banco do Brasil e na Caixa Econômica Federal seguida do Sicoob } \\
\text { Credivale e da AC Credi. Desta forma, pode-se fazer a seguinte inferência, se há } \\
\text { evidências que os entrevistados possuem duas contas no sistema financeiro, uma delas } \\
\text { é em algum dos bancos e a outra provavelmente será em uma cooperativa. }\end{array}$ \\
\hline $\begin{array}{l}\text { Quantidade de } \\
\text { serviços utilizados }\end{array}$ & $\begin{array}{l}59 \% \text { utilizam apenas 1 tipo de serviço; 35\% dois; 5\% 03 tipos de serviços. Menos de } \\
1 \% \text { utilizaram quatro serviços. }\end{array}$ \\
\hline Serviços utilizados & $\begin{array}{l}44,31 \% \text { pagar boletos; 35,29\% fazer depósitos; 9,41\% empréstimos; 4,51\% abertura } \\
\text { de conta; 6,47\% outros. }\end{array}$ \\
\hline $\begin{array}{l}\text { Frequência de } \\
\text { visitas }\end{array}$ & $\begin{array}{l}37,20 \% \text { uma vez por mês; } 19 \% \text { duas vezes por mês; } 15,8 \% \text { uma vez por semana; } \\
14,7 \% \text { mais de uma vez por semana; 13,3\% todos os dias da semana. }\end{array}$ \\
\hline
\end{tabular}

Fonte: Dados da pesquisa (2014) 
Com os dados obtidos pode-se afirmar que a maior parte dos entrevistados que têm conta em cooperativa já possuem alguns anos de movimentação, sendo que a maior representatividade percentual foi dos cooperados que tem mais de 06 anos de associação cooperativista, cerca de $17 \%$. Os que possuem conta entre 03 e 06 anos são mais de $15 \%$, já 2,6\% não lembram o tempo. Dos 347 entrevistados, 122 não possuem conta em nenhuma cooperativa, conforme Tabela 04 .

Tabela 04 - Tempo de conta na cooperativa

\begin{tabular}{ccccc}
\hline & Frequência & Porcentagem & $\begin{array}{c}\text { Porcentagem } \\
\text { válida }\end{array}$ & $\begin{array}{c}\text { Porcentagem } \\
\text { acumulada }\end{array}$ \\
\hline \hline Há menos de 01 ano & 29 & 8,4 & 12,9 & 12,9 \\
Mais de 01 e menos de 03 anos & 49 & 14,1 & 21,8 & 34,7 \\
Mais de 03 e menos de 06 anos & 54 & 15,6 & 24,0 & 58,7 \\
Mais de 06 e menos de 09 anos & 59 & 17,0 & 26,2 & 84,9 \\
Mais de 09 e menos de 12 anos & 11 & 3,2 & 4,9 & 89,8 \\
Mais de 12 e menos de 15 anos & 03 & 0,9 & 1,3 & 91,1 \\
Mais de 15 anos & 11 & 3,2 & 4,9 & 96,0 \\
Não lembro & 09 & 2,6 & 4,0 & 100,0 \\
\hline Total & 225 & 64,8 & 100,0 & \\
\hline Não responderam & 122 & 35,2 & & \\
Total amostra & 347 & 100,0 & & \\
\hline
\end{tabular}

Fonte: Dados da pesquisa (2014)

O principal motivo que levou os entrevistados a se associar e a se manter associado às cooperativas foi $o$ atendimento diferenciado, os benefícios econômicos que as mesmas proporcionam a seus associados, como por exemplo a remuneração da cota capital integralizada por cada um dos associados no ato da abertura da conta corrente, destacando-se também, como benefícios as taxas de juros mais baixas, conforme Tabela 05 .

\section{Tabela 05 - Motivos que levam a se associar}

\begin{tabular}{lcccc}
\hline & Frequência & Porcentagem & $\begin{array}{c}\text { Porcentagem } \\
\text { válida }\end{array}$ & $\begin{array}{c}\text { Porcentagem } \\
\text { acumulada }\end{array}$ \\
\hline \hline Rede de relacionamentos/ & 31 & 8,9 & 13,8 & 13,8 \\
Contato pessoal & & 25,1 & 38,7 & 52,5 \\
Atendimento diferenciado & 87 & 18,4 & 28,4 & 80,9 \\
Benefícios econômicos & 64 & 9,8 & 15,1 & 96,0 \\
Indicação & 34 & 2,6 & 4,0 & 100,0 \\
Outro & 09 & 64,8 & 100,0 & \\
\hline \multicolumn{1}{c}{$\quad$ Total } & 225 & 35,2 & & \\
\hline \multicolumn{1}{c}{ Não responderam } & 122 & 100,0 & & \\
$\quad$ Total amostra & 347 & & & \\
\hline
\end{tabular}

Fonte: Dados da pesquisa (2014)

Já a Tabela 06 vem demonstrar os dados obtidos da análise da estatística descritiva, a qual retrata a média das respostas, bem como a média e a moda, o desvio padrão e a variância. Neste bloco o menor desvio padrão encontrado foi a quantidade de serviços utilizados pelos entrevistados, a média, mediana e moda ficaram em torno de (1) um serviço. As demais variáveis com exceção da quantidade de contas, apresentaram medidas de tendência central e medidas de dispersão variadas. 
Tabela 06 - Bloco 02 - Utilização dos serviços

\begin{tabular}{lcccccc}
\hline \multicolumn{1}{c}{ Variável } & N & Média & Mediana & Moda & $\begin{array}{c}\text { Desvio } \\
\text { padrão }\end{array}$ & Variância \\
\hline \hline $\begin{array}{l}\text { Quantidade de contas no SF [Qcont] } \\
\begin{array}{l}\text { Quantidade de serviços utilizados } \\
\text { [Qserv] }\end{array}\end{array}$ & 347 & 1,77 & 2 & 2 & 0,771 & 0,595 \\
$\begin{array}{l}\text { Frequência de visitas na agência } \\
\text { [freq] }\end{array}$ & 347 & 2,48 & 2 & 1 & 1,445 & 2,088 \\
$\begin{array}{l}\text { Tempo de cooperação [tcoop] } \\
\begin{array}{l}\text { Motivos que levaram a se associar } \\
{[\text { mot }]}\end{array}\end{array}$ & 225 & 3,30 & 3 & 4 & 1,774 & 3,147 \\
\hline
\end{tabular}

Fonte: Dados da pesquisa (2014)

\subsection{Análise da avaliação dos serviços}

O terceiro bloco do roteiro de entrevista visou analisar a avaliação dos serviços pelo usuário, deste modo, foi analisado a satisfação em relação ao atendimento, produtos e serviços, taxas e tarifas e tempo para ser atendido. Buscou-se saber também, o grau de conhecimento sobre cooperativismo, sobre os temas financeiros básicos para gestão do dinheiro, quanto à burocracia, confiança e interesse da cooperativa pela comunidade onde está inserida

\section{Quadro 03 - Avaliação dos Serviços pelo Usuário}

\begin{tabular}{|c|c|}
\hline $\begin{array}{c}\text { Cooperativas como primeira opção em utilizar } \\
\text { os serviços }\end{array}$ & $51 \%$ sim; $49 \%$ não \\
\hline Cooperativas são melhores que outros bancos & $74,4 \%$ sim; $25,6 \%$ não \\
\hline Indicação da cooperativa para outros usuários & 90,5\% sim; 9,5\% não \\
\hline Satisfação com atendimento & $\begin{array}{c}53,31 \% \text { muito satisfeitos; } 29,11 \% \text { satisfeito; } 12,39 \% \\
\text { indiferente; } 4,32 \% \text { ligeiramente insatisfeito; } 0,86 \% \text { muito } \\
\text { insatisfeito. }\end{array}$ \\
\hline Satisfação com educação e cortesia & $\begin{array}{l}63,98 \% \text { muito satisfeito; } 29,11 \% \text { satisfeito; } 3,75 \% \text { indiferente; } \\
2,02 \% \text { ligeiramente insatisfeito; } 1,15 \% \text { muito insatisfeito. }\end{array}$ \\
\hline Satisfação com produtos & $\begin{array}{l}\text { 40,65\% muito satisfeito; } 29,27 \% \text { satisfeito; } 23,98 \% \text { indiferente; } \\
\text { 4,47\% ligeiramente insatisfeito; } 1,63 \% \text { muito insatisfeito. }\end{array}$ \\
\hline Satisfação com serviços & $\begin{array}{l}43,12 \% \text { muito satisfeito; } 39,45 \% \text { satisfeito; } 14,37 \% \text { indiferente; } \\
2,14 \% \text { ligeiramente insatisfeito; } 0,92 \% \text { muito insatisfeito. }\end{array}$ \\
\hline Localização da cooperativa & $\begin{array}{c}72,62 \% \text { muito satisfeito; } 19,31 \% \text { satisfeito; } 3,75 \% \text { indiferente; } \\
1,15 \% \text { ligeiramente insatisfeito; } 3,17 \% \text { muito insatisfeito. }\end{array}$ \\
\hline Satisfação com tarifas e taxas & $\begin{array}{c}\text { Conforme Tabelas } 07 \text { e } 08 \text {, percebe-se que há poucas } \\
\text { modificações em percentuais em comparação com as duas } \\
\text { Tabelas, isso se deve pela semelhança entre as duas. Na } \\
\text { maioria das vezes, os entrevistados optaram pela mesma } \\
\text { avaliação para as duas perguntas, mesmo sendo totalmente } \\
\text { diferentes uma da outra. }\end{array}$ \\
\hline Tempo de espera para ser atendido & $\begin{array}{c}34,01 \% \text { muito satisfeito; } 37,18 \% \text { satisfeito; } 23,34 \% \text { indiferente; } \\
1,73 \% \text { ligeiramente insatisfeito; } 3,75 \% \text { muito insatisfeito. }\end{array}$ \\
\hline Conhecimento sobre o cooperativismo & $\begin{array}{c}31,99 \% \text { nenhum conhecimento; } 25,94 \% \text { indiferente; } 15,27 \% \\
\text { total conhecimento; } 14,7 \% \text { pouco conhecimento; } 12,10 \% \\
\text { conhece. }\end{array}$ \\
\hline
\end{tabular}




\begin{tabular}{|c|c|}
\hline $\begin{array}{c}\text { Informações básicas para gestão do dinheiro } \\
\text { Avaliação do nível de burocracia das } \\
\text { cooperativas }\end{array}$ & $\begin{array}{c}32,28 \% \text { indiferente; } 26,8 \% \text { conhece; } 24,78 \% \text { total } \\
\text { conhecimento; } 9,8 \% \text { pouco conhecimento; } 6,34 \% \text { nada de } \\
\text { conhecimento. }\end{array}$ \\
\hline $\begin{array}{c}\text { Nível de confiança na cooperativa pelos } \\
\text { usuários }\end{array}$ & $\begin{array}{c}30,17 \% \text { pouco burocrática; } 23,71 \% \text { indiferente; } 16,81 \% \text { muita } \\
\text { burocracia; } 14,66 \% \text { burocrática; } 14,66 \% \text { nada burocrática. }\end{array}$ \\
\hline $\begin{array}{c}170 \text { entrevistados têm muita confiança; } 79 \text { confiam; } 71 \\
\text { indiferentes; } 10 \text { têm pouca confiança; } 08 \text { nada de confiança. }\end{array}$ \\
\hline $\begin{array}{c}\text { Interesse da cooperativa pela comunidade (se } \\
\text { trabalham para o desenvolvimento sustentado } \\
\text { de suas comunidades) }\end{array}$ & $\begin{array}{c}36,89 \% \text { total interesse; } 27,95 \% \text { interessa; } 24,50 \% \text { indiferente; } \\
8,36 \% \text { pouco interesse; } 2,31 \% \text { nada de interesse. }\end{array}$ \\
\hline
\end{tabular}

Fonte: Dados da pesquisa (2014)

Tabela 07 - Satisfação com as tarifas

\begin{tabular}{lcccc}
\hline & Frequência & Porcentagem & $\begin{array}{c}\text { Porcentagem } \\
\text { válida }\end{array}$ & $\begin{array}{c}\text { Porcentagem } \\
\text { acumulada }\end{array}$ \\
\hline \hline Muito insatisfeito & 8 & 2,3 & 3,6 & 3,6 \\
Ligeiramente & 8 & 2,3 & 3,6 & 7,1 \\
insatisfeito & 69 & 19,9 & 30,7 & 37,8 \\
Indiferente & 81 & 23,3 & 36,0 & 73,8 \\
Satisfeito & 59 & 17,0 & 26,2 & 100,0 \\
Muito satisfeito & 225 & 64,8 & 100,0 & \\
\hline \multicolumn{1}{c}{ Total } & 122 & 35,2 & & \\
\hline \multicolumn{1}{c}{ Não cooperados } & 347 & 100,0 & & \\
\hline \multicolumn{1}{c}{ TOTAL } & & & &
\end{tabular}

Fonte: Dados da pesquisa (2014).

Tabela 08 - Satisfação com as taxas

\begin{tabular}{lcccc}
\hline & Frequência & Porcentagem & $\begin{array}{c}\text { Porcentagem } \\
\text { válida }\end{array}$ & $\begin{array}{c}\text { Porcentagem } \\
\text { acumulada }\end{array}$ \\
\hline \hline Muito insatisfeito & 8 & 2,3 & 3,6 & 3,6 \\
Ligeiramente insatisfeito & 10 & 2,9 & 4,4 & 8,0 \\
Indiferente & 69 & 19,9 & 30,7 & 38,7 \\
Satisfeito & 83 & 23,9 & 36,9 & 75,6 \\
Muito satisfeito & 55 & 15,9 & 24,4 & 100,0 \\
\hline \multicolumn{1}{c}{ Total } & 225 & 64,8 & 100,0 & \\
\hline \multicolumn{1}{c}{ Não cooperados } & 122 & 35,2 & & \\
$\quad$ TOTAL & 347 & 100,0 & & \\
\hline
\end{tabular}

Fonte: Dados da pesquisa (2014)

O bloco 03 do roteiro de entrevista buscou identificar o nível de conhecimento sobre o cooperativismo e sobre conceitos financeiros úteis para gerir o dinheiro (literacia financeira) além, da burocracia nos procedimentos, confiança na cooperativa e o interesse da mesma pela comunidade.

A Tabela 09 traz as médias obtidas, juntamente com a variância e o desvio padrão das respostas coletadas. Percebe-se que a variável "confiança na cooperativa" apresentou a maior média, sendo 4,18, ou seja, que os entrevistados confiam na cooperativa. 
Tabela 09 - Outas variáveis do Bloco 03

\begin{tabular}{lcccc}
\hline \multicolumn{1}{c}{ Variável } & N & Média & $\begin{array}{c}\text { Desvio } \\
\text { padrão }\end{array}$ & Variância \\
\hline \hline Conhecimento sobre cooperativismo & 347 & 2,64 & 1,426 & 2,035 \\
Informações básicas para gestão do & 347 & 3,54 & 1,151 & 1,324 \\
dinheiro & 225 & 3,11 & 1,304 & 1,702 \\
Burocracia nos procedimentos & 344 & 4,18 & 1,006 & 1,012 \\
$\begin{array}{l}\text { Confiança na cooperativa } \\
\begin{array}{l}\text { Interesse da cooperativa pela } \\
\text { comunidade }\end{array}\end{array}$ & 347 & 3,89 & 1,071 & 1,146 \\
\hline
\end{tabular}

Fonte: Dados da pesquisa (2014)

Procurou-se ciência se os entrevistados possuíam informações sobre temas e conceitos financeiros básicos e úteis para a gestão do dinheiro, mais conhecida por literacia financeira. Segundo Huston (2012), a deficiência de literacia financeira pode afetar um indivíduo ou uma família na gestão do dinheiro do dia-a-dia e na capacidade de economizar para objetivos de longo prazo.

Partindo deste conceito, a análise da frequência das respostas mostrou que em torno de $16 \%$ não possui "nenhum conhecimento" ou possui "pouco conhecimento" sobre mecanismos financeiros para administrar sua própria renda.

Huston (2012) cita também, que as pessoas que apresentam maior nível de literacia financeira têm maior potencial para fazer escolhas informadas e adequadas, e são cerca de duas vezes mais propensas a pagar menores taxas de juros em relação do que àquelas com menor nível de literacia.

Foi inserido no roteiro de entrevista uma questão aberta, ou seja, abriu-se uma oportunidade para que os mesmos pudessem expressar sua opinião quanto ao que se poderia melhorar em termos de produtos e serviços oferecidos pelas cooperativas.

A maioria dos entrevistados não souberam ou não quiseram apontar sugestões, outro percentual considerável disse que "não precisa mudar nada", as demais respostas pouco variaram, sendo que as sugestões recaíram sobre os caixas eletrônicos os quais, segundo os entrevistados precisam de uma maior quantidade destes na agência.

\subsection{Análise do Acesso às Cooperativas por Associados e Não Associados}

Por meio da análise de regressão logística, avaliou-se os fatores determinantes da utilização dos serviços financeiros das cooperativas de crédito por associados e não associados às 3 cooperativas de crédito do município de Teófilo Otoni em Minas Gerais. Sendo assim, foi rodado um modelo de regressão considerando como variável dependente o acesso aos serviços se associado ou não associado.

$\mathrm{O}$ modelo de regressão logístico considerado utilizou o método Forward Stepwise: Wald, já que neste método cada variável é incluída separadamente em cada passo do modelo e é analisado seu desempenho em estimar o "status" de um usuário dos serviços financeiros.

O processo termina quando as variáveis que melhor explicam conjuntamente a variável binária "status" sejam selecionadas, chegando ao modelo final, sendo que das 30 variáveis dependentes, 6 foram consideradas no modelo, conforme Tabela 10 . 
Tabela 10 - Testes de coeficientes de modelo Omnibus

\begin{tabular}{|l|l|}
\hline Nome da variável & \multicolumn{1}{c|}{ Descrição } \\
\hline Ren & Rendimento compreendido entre um e acima de cinco salários mínimos. \\
\hline Qserv & Quantidade de serviços utilizados. \\
\hline Popc & Cooperativa como primeira opção em utilizar os serviços bancários. \\
\hline Mban & Cooperativa melhor que bancos. \\
\hline Ind & Indicação da cooperativa. \\
\hline Loc & Localização da cooperativa \\
\hline
\end{tabular}

Fonte: Dados da pesquisa (2014)

Como pode-se verificar na Tabela 11, as variáveis foram selecionadas em 6 etapas e observase que, no $6^{\circ}$ passo, o modelo apresenta adequação estatisticamente significativa, rejeitando a hipótese de que as variáveis explicativas não explicam a variável dependente "status".

Tabela 11 - Testes de coeficientes de modelo Omnibus

\begin{tabular}{|cc|c|c|c|}
\hline & & Qui-quadrado & df & Sig. \\
\hline Etapa 1 & Etapa & 93,122 & 1 &, 000 \\
& Bloco & 93,122 & 1 &, 000 \\
& Modelo & 93,122 & 1 &, 000 \\
\hline Etapa 2 & Etapa & 19,007 & 1 &, 000 \\
& Bloco & 112,129 & 2 &, 000 \\
& Modelo & 112,129 & 2 &, 000 \\
\hline Etapa 3 & Etapa & 13,968 & 1 &, 000 \\
& Bloco & 126,097 & 3 &, 000 \\
& Modelo & 126,097 & 3 &, 000 \\
\hline Etapa 4 & Etapa & 10,641 & 1 &, 001 \\
& Bloco & 136,737 & 4 &, 000 \\
& Modelo & 136,737 & 4 &, 000 \\
\hline Etapa 5 & Etapa & 8,218 & 1 &, 004 \\
& Bloco & 144,955 & 5 &, 000 \\
& Modelo & 144,955 & 5 &, 000 \\
\hline Etapa 6 & Etapa & 6,593 & 1 &, 010 \\
& Bloco & 151,548 & 6 &, 000 \\
& Modelo & 151,548 & 6 &, 000 \\
\hline
\end{tabular}

Fonte: Dados da pesquisa (2014)

Adicionalmente verificamos a adequação do modelo logístico, sendo que de acordo com Hair et al. (2005), um modelo é bem ajustado quanto menor for o valor de "-2 log Likelihood". De acordo com a tabela 3 verificou-se pelos resultados que a cada passo esse valor foi reduzindo, indicando que conforme as variáveis foram sendo introduzidas no modelo, sua adequação foi melhorando, passando de 356,883 para 298,457 na etapa 6 . As outras medidas (Cox \& Snell e Nagelkerke) também indicam a qualidade do ajuste geral do modelo, com poder explicativo de $35,4 \%$ e $48,70 \%$, respectivamente.

De acordo com Hair et al. (2005), estas medidas de adequação de ajuste comparam as probabilidades estimadas com as probabilidades observadas, sendo que os valores mais altos significam um melhor ajuste do modelo. 
Tabela 12 - Resumo do modelo

\begin{tabular}{|c|c|c|c|}
\hline Etapa & $\begin{array}{c}\text { Verossimilhan } \\
\text { ça de log -2 }\end{array}$ & $\begin{array}{c}\text { R quadrado } \\
\text { Cox \& Snell }\end{array}$ & $\begin{array}{c}\text { R quadrado } \\
\text { Nagelkerke }\end{array}$ \\
\hline 1 & $356,883^{\mathrm{a}}$ &, 235 &, 324 \\
2 & $337,876^{\mathrm{b}}$ &, 276 &, 380 \\
3 & $323,909^{\mathrm{b}}$ &, 305 &, 419 \\
4 & $313,268^{\mathrm{b}}$ &, 326 &, 448 \\
5 & $305,050^{\mathrm{b}}$ &, 341 &, 470 \\
6 & $298,457^{\mathrm{b}}$ &, 354 &, 487 \\
\hline
\end{tabular}

a. Estimação finalizada no número de iteração 4 porque as estimativas de parâmetro mudaram foram alteradas para menos de, 001 .

b. Estimação finalizada no número de iteração 5 porque as estimativas de parâmetro mudaram foram alteradas para menos de ,001.

Fonte: Dados da pesquisa (2014)

Para Hair et al. (2005), a medida final de ajuste do modelo pode ser analisada através do teste de "Hosmer and Lemeshow". Esse teste mede a correspondência entre os valores reais e os previstos da variável dependentes, ou seja, a variável "status".
Um bom ajuste de modelo é indicado por um valor de qui-quadrado não significante. Esse teste verifica a hipótese de que os valores previstos estão próximos dos valores observados de chance contra uma hipótese de que isso não acontece.

Tabela 13 - Teste de Hosmer e Lemeshow

\begin{tabular}{|c|c|c|c|}
\hline Etapa & Qui-quadrado & $\mathrm{df}$ & Sig. \\
\hline 1 &, 000 & 0 &. \\
2 & 10,459 & 7 &, 164 \\
3 & 5,713 & 7 &, 574 \\
4 & 9,141 & 8 &, 331 \\
5 & 10,011 & 8 &, 264 \\
6 & 16,516 & 8 &, 036 \\
\hline
\end{tabular}

Fonte: Dados da pesquisa (2014)

Para avaliar a capacidade de o modelo logístico prever as chances de um não associado utilizar os serviços de uma cooperativa de crédito, verifica-se na Tabela 14 a classificação dos casos previstos pelo modelo, comparando com os dados reais da variável dependente. Verifica-se que de uma forma geral, $77,5 \%$ dos associados são classificados de forma correta, e o percentual de classificação correta para a utilização de associados utilizarem os serviços é de $88 \%$ e para não associados é de $58,2 \%$. Portanto, o modelo estimado tem uma capacidade maior de prever a utilização dos serviços por associados, como era de se esperar. Entretanto, há que se destacar a probabilidade de que $28 \%$ dos usuários de serviços financeiros das cooperativas de crédito sejam realizados por não associados, o que sem dúvidas representa custo adicional para as agências por suportá-los, mas permite uma maior abrangência e socialização de serviços financeiros no município de Teófilo Otoni. 
Tabela 14 - Tabela de Classificação ${ }^{a}$

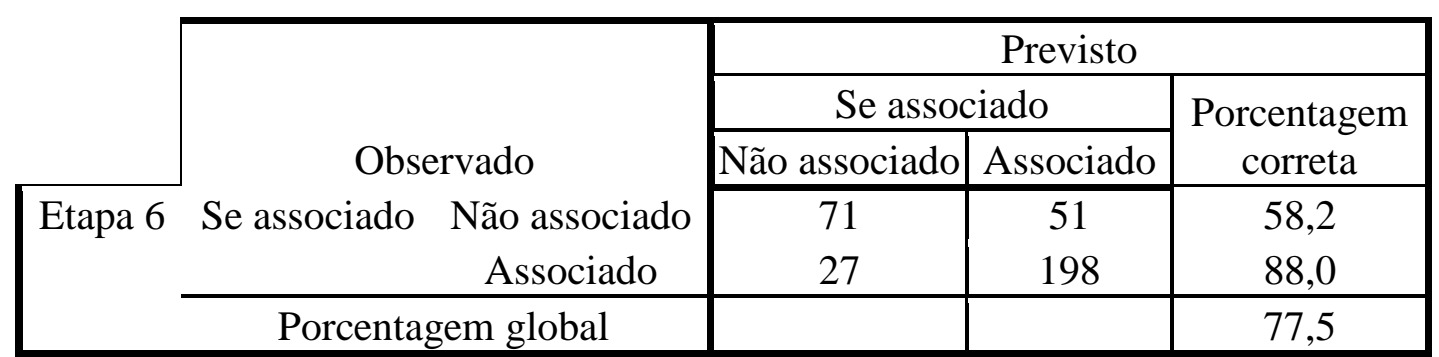

Fonte: Dados da pesquisa (2014)

a. $\mathrm{O}$ valor de recorte é ,500

A Tabela 15 apresenta as variáveis que foram consideradas no modelo, e na coluna "B" são apresentados os coeficientes do modelo para cada variável explicativa. Na sequência temos a coluna "S.E", que apresenta uma medida de variabilidade destes coeficientes, as colunas "Wald" e "sig" são utilizadas para testar a hipótese de cada coeficiente do modelo de regressão. Segundo Hair et al. (2005), esse teste irá identificar o quanto à variável explicativa participa individualmente da explicação da variável dependente. A estatística de Wald testa para cada coeficiente das variáveis do modelo a seguinte hipótese de que o coeficiente da variável explicativa é igual a zero contra uma hipótese alternativa de que não são iguais a zero.

Tabela 15 - Variáveis na equação

\begin{tabular}{|c|c|c|c|c|c|c|c|c|c|}
\hline & & & & & & & & $\begin{array}{r}95 \% \\
\mathrm{EX} \\
\end{array}$ & $\begin{array}{l}\text { para } \\
\text { B) }\end{array}$ \\
\hline & & B & S.E. & Wald & $\mathrm{df}$ & Sig. & $\operatorname{Exp}(B)$ & Inferior & Superior \\
\hline Etapa 6 & ren & ,413 & , 105 & 15,460 & 1 &, $000 * *$ & 1,512 & 1,230 & 1,857 \\
\hline & Qserv & 739 & ,297 & 6,190 & 1 &, $013 * *$ & 2,093 & 1,170 & 3,744 \\
\hline & Popç & -951 & ,296 & 10,294 & 1 &, $001 * *$ & ,386 & ,216 & 691 \\
\hline & Mban & $-1,900$ & ,342 & 30,854 & 1 &, $000 * *$ &, 150 & ,077 & 292 \\
\hline & ind & $-1,374$ & ,539 & 6,504 & 1 &, $011 * *$ & ,253 & ,088 & ,728 \\
\hline & loc & ,556 & , 171 & 10,593 & 1 &, $001 * *$ & 1,744 & 1,248 & 2,437 \\
\hline & Constante & 1,298 & 1,173 & 1,225 & 1 & ,268 & 3,663 & & \\
\hline
\end{tabular}

Fonte: Dados da pesquisa (2014)

Desta forma, pode-se depreender da tabela 15 que as variáveis relativas ao rendimento compreendido entre um e cinco salários mínimos "Ren", quantidade de serviços utilizados "Qserv" e Localização da cooperativa "Loc" possuem coeficientes " $\mathrm{B}$ " positivos, ou seja, são as variáveis preditoras ao acesso dos serviços prestados pelas cooperativas de crédito no município de Teófilo Otoni pelos seus associados, categorizados como baixa renda, usuários de apenas um serviço financeiro e muito satisfeitos com a localização da cooperativa, respectivamente.

Por outro lado, as variáveis cooperativa como primeira opção em utilizar os serviços bancários 
"Popç", cooperativa melhor que bancos "Mban" e indicação da cooperativa "Ind" são as determinantes para o acesso aos serviços pelos não associados às cooperativas de crédito, caracterizadas pelo fato de considerarem a cooperativa como primeira opção em serviços financeiros, melhores que os bancos comerciais e influenciados por indicações de terceiros a utilizarem os serviços.

Neste contexto, os resultados produzidos pela regressão das variáveis são em parte semelhantes àqueles obtidos em estudos realizados por Jossefa (2011), Delgado (2009) e Sartori (2009). O resultado do estudo de Jossefa (2011) é consistente com a hipótese de que os fatores comportamentais não devem ser ignorados, podendo ser inclusive mais expressivos que os fatores socioeconômicos no acesso ao sistema financeiro.

Os outros dois estudos são categóricos no que diz respeito aos fatores comportamentais, satisfação com o atendimento e confiança. Ambos revelam que à medida que aumenta a satisfação, aumenta a procura pelo serviço e até mesmo a confiança na instituição, uma relação que pode ser percebida neste estudo sobre o acesso às cooperativas, já que o atendimento personalizado/diferenciado que as cooperativas oferecem foi o principal motivo que os levaram a se associar.

\section{Conclusões}

Com a crescente participação no movimento bancário do país e com o aumento das autorizações de funcionamento concedidas às Cooperativas de Crédito pelo Banco Central, tornou-se viável e necessário investigar os possíveis fatores determinantes de acesso às cooperativas, visto que elas atuam similarmente aos bancos e os últimos são mais procurados.

A inclusão financeira da população brasileira depende do acesso efetivo a serviços financeiros adequados às suas necessidades, existindo, porém, diversas barreiras ao seu acesso, tais como alto custo de produtos, falta de informação, exigência de colaterais, entre outros. Todavia, a presença de um canal de acesso é a condição mais imediata e trivial para que se possa usar esses serviços, neste sentido as cooperativas de crédito se enquadram neste contexto pois, elas oferecem os mesmos produtos e serviços que as demais instituições com condições mais favoráveis, ou seja, a um custo menor.
O objetivo geral deste estudo foi alcançado quando apresentou os fatores de acesso dos cooperados às cooperativas de crédito do município de Teófilo Otoni e caracterizou os usuários do sistema cooperativista. A partir da análise de regressão logística, pôde-se conhecer os fatores que mais determinam o acesso às cooperativas de crédito do município de Teófilo Otoni, são os que seguem: rendimento compreendido entre um e cinco salários mínimos; baixa quantidade de serviços utilizados; as cooperativas são a primeira opção em utilizar os serviços bancários; as cooperativas são consideradas melhores que os bancos; indicação da cooperativa; localização da cooperativa.

Como sugestão de investigação futura indica-se a avaliação de um número maior de municípios com o objetivo de uma compreensão mais profunda e extensa do comportamento dos usuários dos serviços financeiros das cooperativas de crédito, até mesmo, com a inclusão de outras variáveis comportamentais. Como continuidade dessa pesquisa sugere-se a avaliação, em separado, do acesso aos serviços pelos cooperados e pelos não cooperados, uma vez que o amplo acesso aos serviços pode acarretar maior custo aos pontos de atendimento.

\section{Referências}

ASSAF NETO, Alexandre. Mercado Financeiro. 12. ed. São Paulo: Atlas, 2014.

BANCO CENTRAL DO BRASIL - BACEN. O que é cooperativa de crédito? Disponível em: < http://www.bcb.gov.br/pre/composicao/coopcred.as p>. Acesso em 13 set. 2016.

BANCO CENTRAL DO BRASIL - BACEN. Relação de instituições em funcionamento no país (transferência de arquivos). Disponível em: <http://www.bcb.gov.br/fis/info/instituicoes.asp>. Acesso em 13 set. 2016a.

BANCO CENTRAL DO BRASIL - BACEN. 50 maiores bancos e o consolidado do Sistema Financeiro Nacional, 2014. Disponível em: <http://www4.bcb.gov.br/top50/port/top50.asp>. Acesso em 07 jun. 2014. 
BANCO CENTRAL DO BRASIL - BACEN. Relatório de Evolução do Sistema Financeiro Nacional, 2013. Disponível em: <http://www.bcb.gov.br/?id=REVSFN\&ano>.

Acesso em 01 jun. 2014a.

BEUREN, Ilse M. (Org.). Como elaborar trabalhos monográficos em contabilidade: teoria e prática. 3. ed. São Paulo: Atlas, 2013.

BRESSAN, Valéria Gama Fully; BRAGA, Marcelo José; BRESSAN, Aureliano Angel. Análise da dominação de membros tomadores ou poupadores de recursos nas cooperativas de crédito mineiras. Economia Aplicada, v. 16, n. 2, p. 339-359, 2012.

CORRAR, L. J.; PAULO, E.; DIAS FILHO, J. M. Análise multivariada para os cursos de administração, ciências contábeis e economia. Ed. Atlas, 2014.

DELGADO, Denise Isabel Monteiro. Satisfação do cliente bancário: Estudo em Cabo Verde. 2009. 130 f. Tese de mestrado (Mestrado em Gestão Global) Instituto Universitário de Lisboa, Portugal, 2009. Disponível em: <https://repositorio.iscteiul.pt/handle/10071/2041>. Acesso em: 03 ago. 2014.

GONÇALVES, Rosiane Maria Lima; BRAGA, Marcelo José. Determinantes de risco de liquidez em cooperativas de crédito: uma abordagem a partir do modelo logit multinomial. RAC, Curitiba, v. 12, n. 4, p. 1019-1041, out./dez. 2008.

GUJARATI, D., Econometria Básica. $3^{\text {a }}$ edição, São Paulo: Makron Books, 2006.

HAIR Jr. J. F.; ANDERSON R. E.; TATHAM, R. L.; BLACK, W. C. Análise Multivariada de Dados. 5 ed. Porto Alegre: Bookman, 2005.

HUSTON, S. J. Financial literacy and the cost of borrowing. International Journal of Consumer Studies, n. 36, n. 5, p. 566-572, 2012.

JOSSEFA, Antônio Luciano. Determinantes do acesso ao sistema financeiro: o caso de Moçambique. 2011. 44 f. Dissertação (Mestrado em Economia Monetária e Financeira) - Universidade Técnica de Lisboa, Portugal, 2011. Disponível em: $<$ https://aquila1.iseg.ulisboa.pt/aquila/cursos/emf/di ssertacoes/dissertacoes-concluidas>. Acesso em: 22 ago. 2014.

ORGANIZAÇÃO DAS COOPERATIVAS BRASILEIRAS (OCB). Cooperativas de Crédito e seus Impactos Sociais. Disponível em: <http://www.bcb.gov.br/pre/microfinancas/arquivos /horario_arquivos/trab_50.pdf> Acesso em: 23 set. 2016.

PINHEIRO, Marcos Antônio Henriques. Cooperativas de Crédito: história da evolução normativa no Brasil. 6. ed. Brasília: Banco Central do Brasil, 2008.

PINHO, Diva Benevides. PALHARES, Valdecir Manoel Affonso. O cooperativismo de Crédito no Brasil - do século XX ao século XXI. Brasília: Confebras, 2010.

SANTOS, Ariovaldo dos; GOUVEIA, Fernando Henrique Câmara; VIEIRA, Patrícia dos Santos. Contabilidade das Sociedades Cooperativas. São Paulo: Atlas, 2008.

SARTORI, Simone. Ações de melhoria da satisfação dos clientes de uma cooperativa de crédito. 2009. 121 f. Dissertação (Mestrado em Engenharia de Produção) - Universidade Federal de Santa Maria, Minas Gerais, Santa Maria, 2009. Disponível em: $<$ http://cascavel.ufsm.br/tede/tde_busca/arquivo.ph p?codArquivo=2454>. Acesso em: 02 ago. 2014.

Taylor, R. A. Review of Social Economy, Vol. 29, Routledge, chapter The credit union as a cooperative institution, pp. 207-217. 1971.

TRIOLA, Mario F. Introdução a Estatística: atualização da tecnologia. 11. ed. Rio de Janeiro: LTC, 2013.

VENTURA, Elvira Cruvinel Ferreira (Coord.); FILHO, Joaquim Rubens Fontes (Coord.); SOARES, Marden Maria (Coord.). Governança Coorporativa: diretizes e mecanismos para o fortalecimento da governaça em cooperativas de crédito. Brasília: Banco Central do Brasil, 2009. 
